\title{
«Ni pobres ni ricos, vivimos bien». La lógica del desarrollo y el buen vivir en Ek Balam, Yucatán
}

\section{«Neither Poor, Nor Rich, We Just Live Well». The Logic of Development and buen vivir in Ek Balam, Yucatan}

\author{
Yassir Jesús Rodríguez Martínez \\ Becario Conacyt-Facultad de Ciencias Antropológicas/UADY \\ yassir.rodriguez@correo.uady.mx \\ ORCID: orcid.org/0000-0002-1141-7392
}

Resumen:

El objetivo de este artículo es presentar una crítica al desarrollo desde una investigación realizada en Ek Balam, Yucatán. En primera instancia se aborda cómo la lógica del desarrollo, a través de una serie de representaciones sobre el otro, desvaloriza a los sujetos locales. Seguidamente, se abordan las concepciones locales sobre el vivir bien que posibilitan pensar en alternativas al desarrollo. En conjunto, se plantea la necesidad de mirar más allá del desarrollo y recuperar las voces locales para posibilitar la construcción de diálogos interculturales.

Palabras clave: discurso, campesino, diálogo, otros.

\section{Abstract:}

This article aims to present a criticism to development based on a piece of research carried out in Ek Balam, Yucatan State. It first addresses how the logic of development devalues local subjects through a series of representations of the Other. It subsequently approaches the local notions of buen vivir that make it possible to think about alternatives to development. As a whole, this article posits the need to see beyond development and recover local voices in order to enable the construction of intercultural dialoguing.

Keywords: discourse, peasant, dialogue, the Other. 


\section{Introducción}

a categoría de desarrollo es una fuerza activa que produce intervenciones de todo tipo en diferentes partes del globo y que se presenta con una certeza irrefutable; hoy en día es casi imposible no sentirse atraído y comprometido por la idea de acabar con la pobreza que sufren ciertas personas y regiones de este mundo; también lo es no sumarse a los esfuerzos por cuidar nuestro planeta y discutir el desarrollo desde las ideas de sostenibilidad y sustentabilidad; o qué decir de los intentos de empoderar a las mujeres del llamado "tercer mundo» y generar sociedades mucho más equitativas en lo que respecta a las relaciones de género.

Cada una de estas posibilidades que se desprenden de algún tipo de desarroIlo - económico, sostenible, humano- ha generado que la categoría nos seduzca a todos. Gilbert Rist ubica este panorama de la siguiente forma:

La fuerza del discurso del desarrollo procede de su capacidad de seducción. En todos los sentidos del término: atraer, agradar, fascinar, hacer ilusión, y también engañar, alejar de la verdad, embaucar. ¿Cómo no rendirse a la idea de que pudiera existir un método para eliminar la pobreza que aparece por todas partes? ¿Cómo atreverse a pensar, al mismo tiempo, que el remedio pudiera agravar el mal que se quiere combatir? (Rist 2002:13).

Es tal la fascinación con el desarrollo, que a expensas de las constantes evidencias de su «fracaso», este sigue erigido como una especie de verdad y necesidad incuestionable, ${ }^{1}$ a través de la cual los organismos gubernamentales y las organizaciones no gubernamentales organizan la vida de las personas a fin de conseguirlo.

Poca crítica se ha realizado del desarrollo, quizás lo más común es cuestionar los proyectos ejecutados, pero en cuanto a si cumplen o no con los objetivos que estos mismos plantean como metas a cumplir. De cualquier forma, en los últimos años ha crecido el acercamiento crítico, al pensar en el desarrollo como un discurso hegemónico de occidente a través del cual se realizan intervenciones

\footnotetext{
1 Parte de la fascinación y centralidad del desarrollo en el quehacer político, económico y social de instituciones de diversa índole se debe a su fuerte asociación con categorías tales como modernidad y progreso.
} 
en ciertos espacios y en la vida de las personas (Escobar 1995, 2008). Atender a esta postura permite centrar la atención en la dominación que unos ejercen sobre otros, así como en los efectos que esto genera en la vida de los otros. Ubicar alternativas al desarrollo como premisa organizadora de la vida social es un elemento importante de la crítica a dicha categoría; así, actualmente se discuten posturas alternas como son el posdesarrollo, el socialismo del siglo XXI, el decrecimiento y el Buen Vivir, este último surgido de las poblaciones indígenas de América Latina.

En este artículo presento una postura crítica a partir del análisis de un proyecto de desarrollo en la comunidad maya campesina de Ek Balam, Yucatán. Analizo los discursos que los promotores del desarrollo tienen sobre los otros, en este caso los campesinos de la comunidad, a fin de evidenciar cómo el desarrollo produce un silenciamiento de las voces locales, a través de representar al otro como pobre, necesitado, ignorante y flojo. Al mismo tiempo, recupero las voces de los campesinos para mostrar cómo se conciben a sí mismos y discuto sus concepciones locales sobre el vivir bien, a partir de la categoría buen vivir, como una manera de ubicar en positivo a los sujetos locales.

\section{Desarrollo, posdesarrollo y buen vivir}

En este apartado presento la postura crítica del desarrollo a la cual me adhiero, así como dos categorías que posibilitan pensar en paradigmas alternativos a este: posdesarrollo y buen vivir; esta última como una categoría central para reposicionar las voces locales y romper con la estigmatización de las distintas racionalidades de vida (León 2010).

Como indiqué previamente, el desarrollo puede ser entendido como un discurso que posibilita el control y el manejo de personas y espacios. Un discurso que legitima la intervención de determinados agentes en la vida de las personas y/o en poblaciones consideradas necesitadas de este. Considerar esta postura posibilita centrar la atención en la dominación que unos ejercen sobre otros, así como en los efectos que esto genera en la vida de las personas (Escobar 1995, 2008).

Varios autores (Escobar 1995, Rist 2002, Rahnema y Bawtree 1997) señalan que la «era del desarrollo», que hasta hoy organiza la vida social y económica de las sociedades, inicia con el discurso del presidente estadounidense Harry Truman 
en enero de 1949.2 En dicho mensaje aparece por primera vez el término subdesarrollado (underdeveloped) para referirse a regiones económicamente atrasadas. Este concepto posibilitó la reconceptualización del desarrollo y lo ubicó abiertamente en un nivel político, creándose los mecanismos mediante los cuales ciertas sociedades, que se autodenominaron desarrolladas, han tenido la oportunidad de intervenir en otras sociedades consideradas, a partir de ese momento, subdesarrolladas.

Entonces, a partir del discurso del presidente Truman se estableció un sistema de relaciones entre las sociedades, a través del cual se construyó una práctica discursiva en la cual quedaron establecidas las reglas del juego: quién puede hablar, desde qué puntos de vista, con qué autoridad, y de acuerdo con qué criterios (Escobar 1995). Esta práctica discursiva, estructurada e inmersa dentro de un entramado de relaciones entrelazadas, dio lugar a un proceso en el que se construyó una realidad social de escala global, que posibilitó el establecimiento del desarrollo como algo deseable para todos.

La práctica discursiva del desarrollo ha establecido un nosotros y un otros a través de la creación de "anormalidades» (como pobre, subdesarrollado, malnutrido, ignorante) y de la implementación de un sistema de pensamiento considerado como objetivo, positivo y deseable a través del cual se busca intervenir en las «anormalidades». Es por ello que el desarrollo pensado como discurso, obliga a mirar la relación entre por lo menos dos "grupos», entre aquellos que se presentan como desarrolladores y aquellos a ser desarrollados. Esta relación está constituida por las categorías que los primeros deciden que son correctas y deseables, no solamente en términos de cómo hablar y representar al otro, sino también en cómo solucionar aquello que piensan como problema.

Siguiendo esta idea, se puede decir que uno de los aspectos centrales del discurso del desarrollo consiste en constituir a un otro subdesarrollado, ignorante e incapaz, para después poderlo ayudar a progresar (Hobart 1993). Esta construcción del otro como necesitado, posibilita que los desarrolladores aparezcan como poseedores de conocimiento y pertenecientes a una «mejor» sociedad. Así, las personas pueden ser conceptualizadas de manera diferente dependiendo de su rol: unos serán sujetos activos y otros objetos receptores, unos agentes y otros pacientes, unos tendrán voz y otros serán silenciados.

Por todo lo anterior considero que existe en el discurso del desarrollo una serie de representaciones, estereotipos y prejuicios sobre los agentes, los pacientes y

\footnotetext{
${ }^{2}$ Este discurso se encuentra disponible en <http://www.trumanlibrary.org $>$.
} 
los espacios, que permiten una intervención política, con el fin de extender el dominio de ciertos grupos. Esto no significa — por lo menos no siempre-controlar de manera directa las acciones de los sujetos vistos como pacientes o destinatarios del desarrollo, pero sí permite la reproducción de imágenes, representaciones, estereotipos y prejuicios de las poblaciones vistas como necesitadas de éste. Estas acciones han permitido y legitimado las actividades de ciertos grupos que en nombre del desarrollo han tergiversado las realidades locales, negando en muchas ocasiones la agencia de las personas y sus conocimientos. Siguiendo a Van Dijk (2005), quiero enfocarme en la aplicación del principio polarizante a través del cual se expresa el discurso ideológico del desarrollo; en palabras del autor «... el discurso ideológico es generalmente organizado por una estrategia general de auto-presentación positiva (alarde) y la presentación negativa del otro (detracción)» (Van Dijk 2005:20). Así, en el apartado sobre la mirada al otro desde el discurso del desarrollo, destacaré cómo se expresa un énfasis en las supuestas cosas malas de los indígenas, al mismo tiempo que se esconden u omiten las cosas buenas; en definitiva, atenderé a la polarización que un grupo genera entre un nosotros y un ellos.

Una postura crítica del desarrollo, así como los descontentos ante las fallas empíricas de éste, han permitido que diferentes agentes se pregunten ¿qué hay más allá de él?; precisamente se ha tratado de dar respuesta a esta interrogante a través de la idea del posdesarrollo. Un ejemplo claro de estos esfuerzos es el trabajo colectivo the post-development reader (Rahnema y Bawtree 1997), que contiene un apartado exclusivo para recuperar y expresar reflexiones que den contenido a dicha idea.

Quiero dejar claro que la idea del posdesarrollo no remite a un período histórico al cual se desee arribar o incluso al cual ya hayamos llegado, sino que refiere sobre todo a la posibilidad de pensar en categorías alternas al desarrollo como articuladoras de la vida social. Ciertamente, una forma de pensar en estas categorías es mirar y escuchar a los otros que insistentemente han sido presentados como ignorantes, atrasados y necesitados.

A partir de caracterizar al posdesarrollo de esta forma se puede decir que existe la posibilidad de «... una revaloración de las culturas vernáculas, la necesidad de depender menos de los conocimientos de los expertos y más de los intentos de la gente común de construir mundos más humanos, así como cultural y ecoló- 
gicamente sostenibles». (Escobar 2005:20). Precisamente de las culturas locales ${ }^{3}$ de Ámerica Latina ha surgido el buen vivir, una categoría que da cuenta de la posibilidad de ir más allá del desarrollo, y construir una realidad más amigable con las demás culturas, así como con la naturaleza y los «seres» que la habitan. El buen vivir «sintetiza visiones y prácticas ancestrales, debates y propuestas actuales, el acumulado de pensamiento crítico y luchas sociales de décadas recientes; junta dinámicas nacionales e internacionales de respuesta al "modelo de desarrollo" y al "modelo de civilización" que han conducido a una situación ya reconocida como insostenible» (León T. 2010). En este sentido el buen vivir es inseparable de la diversidad, de las distintas voces que se suman a las propuestas para construir vías alternas al desarrollo, transitar a otros modos de producir, consumir y organizar la vida, tránsito que es posible «mirando y escuchando» a los otros.

De acuerdo a Tortosa (2011) la originalidad del buen vivir, consiste en que la idea proviene del vocabulario de pueblos otrora marginados y excluidos de la respetabilidad. Las dos concepciones más conocidas del buen vivir son sumak kawsay y suma qamaña. De acuerdo a Huanacuni Mamani (2010) los términos utilizados en español para describir el suma qamaña (aymara) y sumak kawsay (quechua) son vivir bien, utilizado en Bolivia, y buen vivir, utilizado en Ecuador; sin embargo, el considera que una traducción más próxima a la cosmovisión indígena para suma qamaña es «vida en plenitud», e igualmente para sumak kawsay, «vida en plenitud».

Si bien estas son las dos concepciones indígenas más conocidas; considero que existen muchas más voces locales que deben ser reconocidas en positivo. Así, las voces locales maya campesinas de Ek Balam ofrecen posibilidades para aumentar el eco del buen vivir y así poder transitar, o por lo menos pensar e imaginar en nuevas lógicas de vida distintas a la ofrecida por el desarrollo.

\section{Ek Balam: entre el turismo y la milpa}

La comunidad de Ek Balam se ubica en el municipio de Temozón, a dos kilómetros de la zona arqueológica del mismo nombre y 30 kilómetros de la ciudad de Valladolid en el Estado de Yucatán, México. Ek Balam es un pueblo pequeño en el que habitan alrededor de 300 personas, de las cuales 281 hablan maya, es

\footnotetext{
3 Escobar indica que el posdesarrollo permite reintroducir una dimensión basada en el lugar; formas subalternas de pensar y modalidades regionales de configurar el mundo se visualizan y posicionan como legítimas (Escobar 2000).
} 
decir el 94\% de la población (INEGI 2010). La principal actividad económica es la agricultura, seguida por la cría y explotación de animales (INEGI 2010).

Es una comunidad que posee «dos realidades» distintas: la de los mayores y la de los jóvenes. Respecto de los primeros, se puede señalar que representan una población vinculada al maíz. El trabajo en la milpa es aún muy importante para ellos, una generación que creció y se formó en una cultura fuertemente apegada a ella y al maíz.

Si bien los adultos mayores persisten en su apego a la milpa, la baja producción del maíz, ha impactado en ellos, y aún más en los jóvenes; éstos últimos, hoy día buscan insertarse en actividades económicas alternas a las agropecuarias, tales como: albañil, taxista, guía de turistas, jardinero, entre otras que se llevan a cabo al interior de la comunidad, pero mayormente fuera de ésta, en lugares tanto cercanos como lejanos.

La migración laboral de los jóvenes no es bien vista por los habitantes mayores de la comunidad, éstos creen que todo aquel que decida salir se verá afectado y corrompido por el alcohol, las drogas y la violencia. Derivado de esta situación, surgió un interés por parte de los adultos mayores de "generar» alguna actividad interna a la comunidad que lograra retener a sus hijos y nietos. La actividad en cuestión fue el turismo.

Actualmente Ek Balam es una comunidad donde ya existe una infraestructura y una dinámica centrada en la actividad turística. Esta situación es producto de un proyecto de desarrollo propuesto por la Comisión Nacional para el Desarrollo de los Pueblos Indígenas ${ }^{5}$ (CDI) en el año 2000 y que tenía como meta la creación de infraestructura para su posterior aprovechamiento en términos turísticos. El resultado de este proyecto es la asociación Uh Najil Ek Balam a cargo del proyecto ecoturístico de la comunidad.

En el año 2004, los ejidatarios de la comunidad, se agruparon en la asociación civil U Najil Ek Balam y en el 2006 constituyeron una cooperativa de responsabilidad limitada denominada Ukuchil Cuxtal, con el fin de facilitar lo relativo a la

${ }^{4}$ El hecho de que hablen maya, no implica que sean monolingües; por el contrario, la mayoría de los habitantes de Ek Balam son bilingües al utilizar constantemente el español.

${ }^{5}$ La historia de cómo nace este proyecto tiene más de una versión. Los ejidatarios de la comunidad señalan que al trabajar como peones en las obras de restauración del sitio arqueológico Ek Balam, platicaron con los arqueólogos sobre la posibilidad de aprovechar la llegada de los turistas. Así, comentan que solicitaron apoyo al entonces Instituto Nacional Indigenista (INI) para conseguir recursos y conformarse como un grupo de trabajo. Los funcionarios de la CDI, por su parte, relatan que el INI levantó un sondeo en la población para conocer problemáticas y a partir de eso decidir el apoyo adecuado para la comunidad: un proyecto turístico. 
comercialización, expedición de facturas, y todo aquello que permitiera un mejor sistema administrativo y contable. Actualmente la CDI, sigue brindando apoyo al proyecto, pero específicamente a través del programa denominado Programa Turismo Alternativo en Zonas Indígenas (PTAZl ${ }^{6}$ ).

La asociación está conformada por un total de 13 socios, ${ }^{7}$ y prestan sus servicios como trabajadores un total de 12 personas - hijos o nietos de los socios-, mayormente en el área del restaurante o como camaristas. También otros jóvenes de la comunidad trabajan en relación a este proyecto, mayormente como guía de turistas.

El proyecto de desarrollo cuenta con doce cabañas que funcionan como alojamiento de los turistas; y se ofrecen servicios de restaurante, senderismo, observación de aves, baño temascal, tour de preparación de tortillas y elaboración de hamacas, visita al sitio arqueológico Ek Balam y al cenote Xcanché, así como tours a las milpas y casas de los habitantes de la comunidad.

Si bien el turismo se encuentra ya presente en la comunidad, los adultos mayores siguen luchando por la persistencia del trabajo campesino; es decir, varios de los ejidatarios de la comunidad alternan sus labores campesinas con las del proyecto de desarrollo. Particularmente, la gente adulta mayor, no quiere dejar de hacer milpa. Esta es conocida en la lengua maya como kool y constituye un:

complejo sistema agrícola que requiere para su producción de la organización familiar, del conocimiento del entorno, de la identificación de los tipos de suelo, de las características de las semillas sembradas y de las temporadas de lluvias y sequías. Al ser la dispensadora del maíz, el principal alimento de la población, la milpa se convierte también en un elaborado sistema simbólico que se expresa en los rituales, los cuales se realizan al tumbar el monte, quemar las milpas, sembrar las extensiones o recoger las cosechas (Lizama Quijano 2007:93).

Uno de los aspectos más comentados por la gente mayor de Ek Balam es su gusto por el trabajo campesino, siempre lo señalan como algo «muy bonito»; las

6 El objetivo de PTAZI es «contribuir al desarrollo de la población indígena, mediante la ejecución de acciones en materia de turismo alternativo, específicamente ecoturismo y turismo rural, aprovechando el potencial existente en las regiones indígenas, otorgando apoyos para elaborar y ejecutar proyectos encaminados a la revaloración, conservación y aprovechamiento sustentable de sus recursos y atractivos naturales, y de su patrimonio cultural, así como para coadyuvar a mejorar sus ingresos, respetando la organización comunitaria de los pueblos indígenas» (CDI 2012).

7 La asociación inició con 23 integrantes, pero 11 dejaron el proyecto al año y medio de iniciar. El abandono fue debido a que consideraban que el proyecto no les daba la ganancia suficiente para poder dejar sus actividades y sí implicaba mucho tiempo y trabajo no remunerado. 
personas se regocijan al contarle a uno la emoción que sienten al ver crecer el maíz, oler la tierra mojada, descansar en su milpa con el fresco del monte, observar los colores de las plantas y árboles, entre muchas otras cosas.

Parte importante de su trabajo y destacado insistentemente por ellos mismos, es la semilla de maíz que utilizan, ya que es una semilla local que no quieren se pierda, a pesar de que el gobierno ha intentado introducir semilla híbrida, como ellos la conocen. El comisario ejidal comentó al respecto de las semillas:

Nosotros la semilla que siempre hemos manejado es una semilla desde muchos años que no queremos que se pierda, porque realmente ha habido oportunidades, de que nos digan saben qué cambia esa semilla, no te da resultados, pero hay su porque, por ejemplo, la semilla que sembramos es un maíz blanco y ese maíz blanco aguanta el sol, no importa que no haiga muy continuo temporada de lluvia, aguanta... más sin embargo, el que le decimos hibrido, pues no, porque ese sí necesita mucho riego y en seguidas lo notas... (don Federico, 2012).

Las semillas que usan las personas de Ek Balam, les permiten tener autonomía en su producción, debido a que éstas no necesitan de fertilizantes, sistemas de riego, herbicidas y otros productos que en su totalidad provienen del mercado externo. Así mismo y como ellos mismos dicen, el sabor del producto obtenido es incomparable. En la comunidad los campesinos trabajan la tierra bajo el sistema de roza, tumba y quema, el cual ha sido objeto de ataques por la supuesta destrucción que implica para la naturaleza; sin embargo, de acuerdo a Terán y Rasmusén (2009), este sistema no sólo no destruye la naturaleza, sino que la conserva, debido a que favorece la fertilidad del suelo. Respecto del ciclo agrícola maya campesino se puede decir lo siguiente:

[Éste] comienza con la búsqueda de un terreno para desmontar, que debe de haber permanecido unos seis o siete años descansando, a fin de que concentre una mínima parte de nutrientes naturales que garanticen una buena cosecha en el primer ciclo de producción. Una vez encontrado y medido el terreno, se tumba, es decir, se limpia de árboles y hierbas, mismas que se dejan secar un tiempo, hasta marzo o abril cuando se realice la quema, también conocida como tóok. Con esto el terreno quedará preparado para poder ser cultivado (Lizama Quijano 2007: 96) [corchetes míos].

Cada campesino dependiendo de la edad, del número de personas en su familia y de las posibilidades que tenga - fuerza y dinero- tumba dos, tres o 
hasta cinco hectáreas de monte; una vez que se tumba, comienzan a preparar la guardarraya, ${ }^{8}$ esto con el objetivo de que cuando se realice la quema (to'ok), el fuego no sobrepase los límites del terreno trabajado para la siembra. Muchas personas ven la quema como uno de los momentos más peligrosos, no tanto por la integridad de las personas, sino sobre todo por el riesgo de destruir el monte alto y así dañar la naturaleza y el hogar de los animales.

Una vez que se realiza la quema, lo que procede es la siembra (pak'al), para lo cual tienen que esperar los indicios de una fuerte lluvia o como dicen algunos de los campesinos "espiar» el tiempo; al momento de sembrar no se siembra solamente maíz, sino también frijol, ibes y calabaza, todos juntos, esto debido a que la milpa es un policultivo y no un monocultivo como muchas veces se piensa (Terán y Rasmussen 2009). La gente trata de sembrar lo más rápido posible, por lo cual trabajan hasta seis o siete horas seguidas, todo con la idea de aprovechar la lluvia9 en grandes cantidades.

No es objetivo de este artículo resaltar cada uno de los componentes biológicos, sociales y simbólicos del trabajo campesino, pero sí es importante destacar, que la milpa involucra una gran cantidad de conocimientos, saberes y formas de relacionarse con la naturaleza que se distancian del conocimiento occidental, y que se verán en peligro por el proyecto de desarrollo turístico.

\section{El otro visto desde la lógica del desarrollo}

En este apartado quiero evidenciar cómo el discurso del desarrollo genera una serie de representaciones en torno a las cuales los habitantes de Ek Balam son identificados como una población pobre, ignorante y necesitada de ayuda externa; en este sentido, los agentes promotores del desarrollo consideran que los campesinos de la comunidad deben aspirar a vivir mejor a través de un trabajo remunerado. Así, el desarrollo no solamente implica tipificar al otro y generar una

${ }^{8}$ La guardarraya, en maya mis pach kol, es una franja que bordea todo el terreno de la milpa, con una medida aproximadamente de dos metros. Esta franja tiene que estar libre de toda hoja, pedazos de madera u cualquier otro elemento que permite prender fuego; la guardarraya también permite al campesino moverse al momento de prender el fuego para la quema y así poder vigilarlo cuando así se requiere.

9 La lluvia es el elemento central del trabajo campesino, y es quizá la mayor preocupación que les embarga, debido a la inseguridad que existe hoy en la precipitación de las lluvias. La centralidad de la lluvia queda por asentado en uno de los rituales agrícolas más conocidos e importantes entre los mayas, la petición o rogación de lluvia, en maya cha'a chaak. 
serie de acciones concretas para transformar las prácticas locales, sino que también acalla e incluso atenta contra lógicas de vida distintas al sistema capitalista neoliberal.

El discurso del desarrollo puede ser entendido como uno que ha sido producido históricamente, ${ }^{10}$ y que se ha reconstituido en distintos grados, pero que todavía se manifiesta y expresa como un mecanismo a través del cual unos grupos representan a otros, y ejercen poder sobre ellos (Escobar 1995, 2008). Lo que aparece en el discurso del desarrollo, independientemente de las instituciones y la espacialidad de la cual se esté hablando, es una serie de representaciones de la gente y de los espacios a los cuales éste va dirigido; asimismo, a través de este discurso se construyen problemas y soluciones específicas para éstos. Como señala Arce (2000), el lenguaje del desarrollo es una forma de enmarcar problemas, atribuir esencias, y encontrar soluciones basadas en la objetivación de lo que constituye el proceso del desarrollo.

De esta forma, el discurso sobre el desarrollo constituye una arena en la cual se decide quiénes son representantes de un problema, y quiénes son capaces de ofrecer conocimiento y herramientas para superarlo. Esto quiere decir, que la categoría desarrollo sólo existe y cobra vigencia, en cuanto se identifican una serie de anormalidades como lo son el iletrado, el subdesarrollado, y el malnutrido.

En México, las anormalidades han sido históricamente asociadas a las poblaciones indígenas, quienes en su conjunto forman el llamado problema indígena, y que ha sido blanco de distintas formas de intervención a propósito de su mejora. La población de Ek Balam forma parte de este escenario amplio en el cual se intenta conducir a una población indígena hacia el desarrollo, lo cual implica, en primera instancia, representar a dicha población como pobre y necesitada. ${ }^{11}$ De esta forma, a continuación me centro en la forma en que los agentes que se vinculan al proyecto de desarrollo Uh Najil, representan a la comunidad y a los sujetos indígenas con los cuales se relacionan.

En México, ser indígena y ser pobre parece ser una realidad incuestionable, es algo que forma parte de las verdades sociales. Como señala Martínez Novo, «lo que convierte a los indígenas en una población que merece ser ayudada no es tanto su especificidad étnica o cultural como su extrema pobreza» (1999: 42).

\footnotetext{
10 Por motivos de extensión, en este trabajo no me detengo a rastrear la historia del desarrollo; al respecto puede verse Escobar (1995), Rist (2002), Preston (1999).

11 En este trabajo no me detengo a señalar cada uno de los mecanismos a través de los cuales se etiqueta a Ek Balam como una comunidad pobre y marginada, sino solamente en las representaciones de los agentes del desarrollo.
} 
Precisamente, cada uno de los agentes de desarrollo que entrevisté, mencionaron que Ek Balam era una comunidad que padecía pobreza, ya sea en términos económicos o incluso en términos culturales, con lo cual se referían a la aparente imposibilidad de los habitantes para pensar y actuar fuera de sus patrones culturales locales. Al respecto Maricruz, ${ }^{12}$ funcionaria de la CDI, me comentó:

Es preocupante el bajo nivel de desarrollo de la comunidad, ves que algunos no tienen agua, no tienen drenaje, la educación está mal...hace falta mucho por darles, viven totalmente aislados, tienen muchas debilidades, CDI lo que busca es darles el apoyo (Maricruz, 2011).

El ingeniero Fernando de la CDI me comentó lo siguiente respecto de la comunidad:

sí es pobre; ellos dependen de la milpa, es una cuestión cultural, no se las puedes quitar de la noche a la mañana, tienen que hacer su milpa y esa milpa les cuesta; los ingresos no son muchos, de pobre a pobre, Actuncoh ${ }^{13}$ es más pobre, Ek Balam dentro de su pobreza tienen potencial y oportunidades de ingreso... (Fernando, 2012).

En concordancia con los dos comentarios anteriores, la licenciada Geovana quien fungió como capacitadora durante unos cursos impartidos a la asociación Uh Najil señaló:

la comunidad no tiene banquetas, cableado seguro, no tienen teléfono, no tienen secundaria, transporte más cercano llega a varios kilómetros, no tienen una plaza central digna, no tienen tiendas, no tienen molino... es decir, tienen infraestructura cero, es un pueblo abandonado (Geovana, 2012).

Mauricio, quien fue coordinador de cursos impartidos por una "prestigiada" universidad privada de Yucatán, señalaba no solamente el tema de la pobreza, sino también el de la marginación: ${ }^{14}$

\footnotetext{
12 No es el propósito de este trabajo hacer señalamientos particulares, por lo cual omito poner el cargo específico de los agentes del desarrollo y señalo que sus nombres han sido cambiados.

13 Actuncoh es un pueblo situado a ocho kilómetros de Ek Balam

14 Respecto al tema de la marginación Mauricio lamentó que el apoyo gubernamental se concentrara solamente en estas comunidades, las cuales, en palabras de Mauricio, muchas veces desperdician y no agradecen los apoyos, ya que hay muchos universitarios o gente preparada que haría muy buenos proyectos/trabajos con esos apoyos.
} 
carecen de todo, no tienen casas dignas, no tienen buenos trabajos, viven en apuros todo el tiempo, viven en pobreza; está claro que es una comunidad marginada, como muchas en el país, tú sabes, las comunidades indígenas en nuestro país son las más marginadas, no llega una buena educación, no tienen médico, sistemas de salud, entre otras cosas (Mauricio, 2012).

En las expresiones anteriores aparece una imagen recurrente en el tema de la pobreza en cuanto discurso; Yapa (1996) menciona que la «pobreza como discurso» es una abstracción conceptual que agrupa varios estados materiales de privación. En este sentido, los agentes externos señalan que carecen de casa dignas, infraestructura, tranquilidad económica («viven en apuros»), buena educación, salud, entre otras cosas. Así, el tema de la pobreza se encuentra frecuentemente ligado al tema de lo económico.

Para los agentes externos, está claro que la solución en Ek Balam, es generar un empleo que le proporcione a las personas un ingreso a través del cual obtener o conseguir todo aquello de lo que carecen; así, el proyecto ecoturístico aparece como la solución a «su pobreza». Como mencioné anteriormente, si bien la pobreza mayormente se entiende en términos materiales y/o económicos, es notorio, que para algunas personas los habitantes de Ek Balam también son pobres por su carencia de iniciativa o disposición al cambio. Un funcionario de la CDI mencionó algo al respecto:

Nadie se arriesga a hacer algo diferente, si no está en el manual no lo hacen; hay como un recetario de la vida cotidiana, todo tiene una forma de hacerse y no se salen de eso... Los varones, solo se dedican al maíz, no saben hacer otra cosa, necesitan una predisposición al cambio (Abraham, 2012).

Ciertamente la predisposición al cambio es uno de los intereses de los agentes externos, cambio que mayormente se relaciona con el abandono del trabajo en la milpa, para la dedicación exclusiva al trabajo turístico; como comentó uno de los capacitadores articulados al proyecto de desarrollo: «lo primero que hay que cambiar en Ek Balam es la tortilla», frase que expresaba claramente la intención de romper la fuerte relación que tienen los habitantes de Ek Balam con el maíz y la milpa.

Derivado de la asociación entre los habitantes de Ek Balam y la pobreza, es impostergable que las voces externas anuncien el inevitable pensar en el desarrollo; para los agentes externos, es casi imposible dudar que la población necesita 
de una vida mejor. Así, se construye un coro que produce una imagen del otro como necesitado, el otro que se convierte en objeto de estudio e intervención con fines de alcanzar el desarrollo.

De las entrevistas y pláticas informales que sostuve con los agentes externos, pude rastrear que independientemente de cómo se pensara el desarrollo, ${ }^{15}$ destacaba la insistencia de la aparente necesidad de la intervención externa para alcanzarlo; dicho de otra forma, el pensamiento compartido es que los indígenas por sí solos serían incapaces de generarlo. De acuerdo con Maricruz el desarrollo consiste en:

Hacer una mejora en las comunidades, esa es la idea, que a través del turismo ellos puedan por ejemplo, no sé, mejorar su calidad de vida, generar ingreso, trabajo dentro de sus mismas comunidades, a lo mejor con eso ya adquirir otro tipo de servicios (Maricruz, 2011).

El ingeniero Fernando comentó su concepción del desarrollo de la siguiente forma:

El desarrollo tiene que ver con los beneficios económicos, llegada de recursos; que llegue gente, asesores; de hecho así ha pasado, han llegado gente y organizaciones externas para investigar, para ayudar al grupo, de España, Francia, Estados Unidos... (Fernando, 2012).

En el comentario del ingeniero Fernando se condensan las distintas posturas ${ }^{16}$ que más destacaron en las entrevistas con los agentes externos, es decir, el desarrollo se relaciona con lo económico y es posible vía ayuda y asesoría externa. Éste necesariamente debe provenir de agentes externos, lo cual implica una necesaria relación entre éstos y los sujetos locales. Así, en Ek Balam la relación entre los primeros y los segundos se expresa sobre todo en visitas, cursos de capacitación, pláticas formales e informales, etc.

¿Cómo se representan los agentes del desarrollo a los sujetos locales con los cuales se relacionan a propósito del desarrollo? En términos generales, el sujeto

15 El desarrollo fue entendido con regularidad como crecimiento económico, creación de infraestructura, y generación de empleos.

${ }^{16}$ En términos generales las distintas personas entrevistadas señalaron que el desarrollo consiste en crecimiento económico, generación de empleos e infraestructura. A expensas de las distintas versiones qué sobre el desarrollo se expresaron, es interesante que cada uno de los agentes externos hizo un esfuerzo por definirlo o por lo menos caracterizarlo. 
indígena es representado por parte de las personas encargadas de las políticas públicas de desarrollo como un sujeto irresponsable, que no se compromete del todo con el proyecto, y que carece de habilidades y malicia para relacionarse con las demás personas. Al respecto de cómo representan a los sujetos de la población de Ek Balam, señalo algunas posturas de trabajadores y directivos de la CDI y otras instituciones que se relacionaban con el proyecto de desarrollo:

Es difícil tratar con personas indígenas, porque no están tan empapados de algunos términos, es difícil que te entiendan que es una responsabilidad y compromiso que tienen hacia nosotros CDI, tienen que rendir cuentas claras, facturas, comprobaciones. La gente se aprovecha de ellos, pecan de inocentes, no tienen malicia [...] no cumplen con las reuniones, no cumplen con el compromiso, darle la importancia cuando vamos o cuando se les requiere para algo (Maricruz, 2011).

Por otra parte Fabrizio, quien fue contratado por la CDI para dirigir cursos de capacitación turística en Ek Balam, piensa que:

Los problemas con trabajar con la gente [indígena] son: falta de educación, mal hábito de esperar que todo lo dé el gobierno, flojera, les da mucha flojera trabajar, mucha flojera aprender, qué otra cuestión, que siempre se escudan en el yo no lo sé hacer, espero que alguien más me lo haga y gratis [...] es que si no me lo da el gobierno no lo puedo hacer, no tienen la mentalidad de los negocios [...] algunos no les gusta relacionarse con otra gente, no les gusta tampoco la cuestión de que alguien fuera de su comunidad sea quien llegue a proporcionarles ayuda, si no lo dice el cacique del pueblo, el ejidatario líder o alguien que tenga un rango importante dentro de la comunidad pocas veces hacen caso de lo que dices, ¿qué más? (Fabrizio, 2012).

En los dos comentarios anteriores se reproducen estereotipos de vieja data respecto de los indígenas. Del comentario de Maricruz, destaca la idea de que los indígenas no se comprometen con la ayuda que quieren proporcionar los agentes externos; «no cumplen con las reuniones, no cumplen con el compromiso», palabras que pierden de vista la variedad de actividades que la gente local realiza, particularmente las actividades del campo; así, la inasistencia a una reunión fijada de manera arbitraria por los agentes externos se interpreta como falta de compromiso y responsabilidad.

El segundo comentario, todavía más directo, reproduce una serie de estereotipos sobre los indígenas mexicanos en cuanto mentirosos, flojos y huraños. Así, 
a través del discurso del desarrollo se expresa una serie de imágenes del indígena, que van desde pensarlos como flojos y tercos, hasta ignorantes y de pensamiento cerrado. Es necesario señalar que cada uno de estos adjetivos, puede ser pensado como un estado que unos sujetos le atribuyen a otros en relación a determinado proceso, en este caso, alcanzar el desarrollo. Así que, en el caso de Ek Balam, ser indígena y necesitado del desarrollo, con frecuencia implica estupidez, fracaso y flojera. Todo lo anterior indica que el discurso del desarrollo que implementan ciertas instituciones, sigue jugando un rol fundamental en la representación del otro como inferior y necesitado. Así, desde la perspectiva de los agentes externos ¿Por qué habría que escuchar las voces locales?, si lo único que representan son un obstáculo para mejorar su propia vida.

\section{Las voces locales en Ek Balam: elementos del vivir bien}

La lógica y discurso del desarrollo ubican a las comunidades indígenas como comunidades de las cuales no hay nada que aprender. A diferencia, el buen vivir posibilita pensar en positivo una serie de ideas, creencias y prácticas emanadas de estas colectividades. El buen vivir parte, necesariamente, de un reconocimiento positivo de la realidad, implica una visibilidad de todas las personas y colectividades desde sus aportes y potencialidades, no sólo desde sus carencias (León 2010).

Antes de revisar lo que considero son los aportes locales de los habitantes de Ek Balam al coro del buen vivir, esbozo brevemente la forma en la que ellos se conciben a sí mismos, destacando de manera particular que no se conciben como pobres. Las veces que conversé con las personas de la comunidad, me decían que no son ni pobres y que por supuesto no son ricos, pero que viven bien, siempre aludían a ese hecho; la constante en las conversaciones fue la expresión: «ni pobres ni ricos, vivimos bien». ${ }^{17}$ Al respecto dos comentarios:

Ni pobres, ni ricos; de rico no, mayormente viven como siempre, tranquilos, ahora hay maíz para hacer tortillas, hubo frijol, no va a comprar frijol, en su milpa lo va a agarrar, frijol, otras cosas, pepita, hubo mayormente regular la cosecha... nadie está rico, pero viven bien, así vivimos. (don Claudio, 2012).

17 Esta expresión cuestiona la visión occidental de la pobreza. Particularmente en Ek Balam la gente considera que uno es pobre cuando se carece de tierras para trabajar la milpa y por ende, obtener los alimentos necesarios para la supervivencia. 
Tenemos lo necesario para comer, con el trabajo no nos falta nada, no nos vamos a enriquecer, pero no falta nada... es cierto, aquí no hay ricos ni pobres, gracias a Dios hay lo necesario para vivir bien... (doña Felipa, 2012).

¿Cómo se articula este «vivimos bien» con los debates sobre el buen vivir? A continuación, esbozaré algunas líneas que considero importantes. La concepción del buen vivir, es un tema que se discute actualmente como reacción y alternativa a los conceptos convencionales sobre el desarrollo (Gudynas 2011). De esta forma es posible decir, que el buen vivir apareció en la escena intelectual y política como una ruptura frente al discurso de lo moderno y el desarrollo, por lo cual muchas «de las manifestaciones del buen vivir son movidas por intentos expresos de volver a otorgar significados y controlar los territorios; es una resignificación de espacios geográficos frente a lo que se considera como invasión o usurpación, no sólo de recursos naturales, sino de los estilos de vida» (Gudynas 2011:11).

De lo anterior se desprende una acotación importante respecto del buen vivir en Ek Balam; es necesario señalar que en esta comunidad el buen vivir no aparece como un movimiento explícito de reivindicación de derechos indígenas, sino que aparece más como aquello que forma parte del conocimiento y de la «mirada» de los habitantes a su propia vida y cómo les gustaría mantenerla. A diferencia de Ek Balam, Michela Giovannini (2014) ha dado cuenta que, en otros territorios de México, particularmente Chiapas, el buen vivir sí se ha manifestado en contextos de reafirmación identitaria, participación en la esfera pública y el reforzamiento de procesos de autonomía. ${ }^{18}$

Una pieza fundamental del buen vivir, que tiene plena vigencia en el pensamiento y acciones de las personas de Ek Balam, es lo relativo a la ruptura de un pensamiento antropocéntrico y cierta forma de relacionarse con la naturaleza a través incluso de «seres» no humanos. Así es, el Buen Vivir «tiene la reputación de basarse en una relación armónica y respetuosa entre seres humanos y entre éstos y los otros seres vivos que cohabitan la naturaleza. Esta noción es atribuida a los pueblos campesinos e indígenas "amerindios" y, en general, a todas las estructuras donde los mecanismos de desarrollo no están basados en la ganancia sino en la producción de satisfactores en armonía con la naturaleza» (García Linera 2010 en Farah y Vasapollo 2011:17).

Me parece que está relación armoniosa entre el hombre y naturaleza a través incluso de otros seres no humanos, aparece en el trabajo campesino, el cual

${ }_{18}$ Michela Giovannini (2014) centra su atención en la relación entre empresas comunitarias indígenas y el buen vivir. 
como señalan los propios habitantes de Ek Balam les permite mantener la vida tranquila que poseen.

El trabajo campesino implica que el hombre entre en contacto con la naturaleza, se relacione con ella, incluso a través de entes que pertenecen al orden de lo sobrenatural, con los cuales también se guarda una estrecha relación. En este caso específico me refiero a los aluxes (kanan koolo'ob). Los aluxes se describen como seres que pueden hacer el bien, pero también el mal, se les representa o piensa como seres pequeños que suelen ser traviesos; se puede decir entonces que «Los aluxes son inquietos y traviesos, pueden jugar con los hombres tan sólo para divertirse. Sin embargo, pueden también proteger la milpa y cuidar de los hombres guiándolos por el camino y ahuyentar a las criaturas que los pueden dañar. Por eso exigen que se les ofrezca comida y bebida, para que se alimenten...» (Lizama Quijano 2007:84).

Los aluxes son considerados los señores protectores del monte y de las milpas; las personas que todavía creen en él, asumen la responsabilidad de alimentar$\operatorname{los}^{19}$ para que los protejan a la hora de trabajar y también para que les cuiden el producto de su trabajo. Don Andrés me comentó al respecto:

Antes de trabajar vas a pedir permiso, de señor de monte, a los aluxes... a veces hay accidente, habiendo malo, mareando, porque veces... pos veces hay castigo, porque no das alimentación, no preguntas, permiso de ese, también el monte tiene dueño... yo sí pido permiso, saco el saká, 13 jicaritas, das permiso de trabajar, nada vas a durante vas a estar tumbando no hay peligro... yo tengo aluxito en mi milpa, doy alimentación (don Andrés, 2012).

Así como don Andrés todavía practica dar alimentación a los aluxes, algunos de sus compañeros del pueblo también lo hacen, siempre bajo la creencia de que éstos son los dueños del monte y pueden ayudar o perjudicarles tanto en su trabajo como en su salud. Si bien los aluxes fueron los más mencionados a la hora de hablar acerca de la protección de la milpa y del trabajo campesino, don Mario me externó que también se debe dar gracias a otros seres, entre los cuales incluso se encuentran algunos animales como el gavilán; don Mario lo señaló de la siguiente forma:

una ofrenda, diferentes maneras, se saca el saká antes de que uno empieza a tumbar la milpa, cuando salen los primeros elotes también se puede hacer la ofrenda completa

\footnotetext{
19 Para conocer acerca del ritual alux kanan kool 'cuidador de milpa' véase Tuz Chi (2013).
} 
y se saca a diferentes cosas que cuidan la milpa, alux, gavilán, chak, ${ }^{20}$ en la primera cosecha del elote, se lleva a cabo eso (don Mario, 2012).

En la cosmovisión maya, los seres humanos entran en relación con la naturaleza a través de una serie de divinidades, entre las cuales destacan los yúumtsilo'ob 'hombres buenos', los balamo'ob 'señores jaguar', Dios (Yuum Ku o Yuum Ahau), los aluxes, los kates. De esta manera existe una gran distancia entre la cosmovisión occidental y las no occidentales como la maya; en la primera, Dios separa al hombre de la naturaleza, y otorga el «poder» a éste para dominarla, someterla y explotarla, mientras que en las segundas el ser humano se encuentra en plena relación con la naturaleza a través de un mundo espiritual, mediante el cual agradece por el sustento y no por la explotación (Roa Avedaño 2009).

Un segundo elemento importante que se puede destacar de la perspectiva local de vida en Ek Balam, es el disfrute de una vida sencilla. De acuerdo a Huanacuni Mamani (2010), el vivir bien desde el pueblo aymara apunta a una vida sencilla que reduzca nuestra adicción al consumo y mantenga una producción equilibrada sin arruinar el entorno; una oposición al pensamiento occidental de vivir mejor ${ }^{21}$ a costa del otro. Esta vida sencilla que implicar vivir bien, se expresa en Ek Balam a través de cuatro elementos: poseer autonomía alimentaria, salud, cercanía con la familia y la tranquilidad del pueblo. Lo más indispensable es que existan alimentos, que cada familia tenga lo suficiente para comer, lo cual además mayormente está representado por el maíz en forma de tortilla, masa y atole. Un segundo elemento de suma importancia es lo relativo a la salud, estar sanos, esto debido a que al estar uno sano se puede dedicar al trabajo en el campo sin ningún contratiempo.

Otro elemento es la tranquilidad del pueblo, la gente realmente parece disfrutar mucho la «falta de problemas» en su comunidad, como por ejemplo la falta de robos y/o asaltos que saben sí existe en las ciudades o incluso en lugares más cercanos a ellos como Temozón; al respecto don Fidel comenta:

Ta tranquilo aquí; aquí no hay maleantes, no hay, ahora en Temozón dicen que hay este, los maleantes... ellos roban, esos flojos, se juntan así, aunque sea una gallina de

\footnotetext{
20 Los chakes son (yuum chako'ob) conocidos en la mitología maya como los señores cuidadores de la lluvia, capaces de hacer llover ante la plegaria de los mortales (Tuz Chi 2013).

21 De acuerdo a Huanucuni Mamani (2010) el vivir mejor implica ganar más dinero, poseer más poder y fama que otro; implica competencia respecto de otros y «mejorar» a costa de otros. Así mismo, implica el progreso ilimitado, consumo inconsciente.
} 
noche, un pavo, lo chingan también, por eso hay maleantes así, aquí no hay, no hay (don Fidel, 2012).

La familia es otro factor importante, estar juntos y disfrutar de la compañía de ésta es una situación que las personas de Ek Balam aprecian, motivo por el cual tratan de buscar opciones laborales que no impliquen una migración definitiva. De cierta manera, todo aquello que se corresponde con esta idea de una vida sencilla y también el respeto por la naturaleza y su visión no antropocéntrica del mundo, se relaciona con el trabajo y la vida campesina. Así, para concluir este apartado, destaco la forma en la que los habitantes de Ek Balam comparten su forma de entender la vida campesina:

Me gusta trabajar en el campo, cosecho, chapeo, voy a leñar, pasar en el monte... de un campesino lo normal, comemos lo que comemos aquí, tomate, frijol, maíz, arroz... los que viven en las ciudades viven de otra forma... en el campo es mejor la vida, a mí me gusta mucho ser campesino. Siembro mis plantitas, siembro chile, como fresco, en ciudad tienes que comprar todo... a mí me encanta ser campesina... (don Felipe, 2012).

Las personas que comentaron no ser pobres, ni ricos, sino vivir bien, tranquilos y felices, parece ser que le dan un gran peso al trabajo campesino; este trabajo como ellos mismos dicen, es un trabajo que no es asalariado, no devenga ingresos como los «nuevos» trabajos, sin embargo, otorga lo que quizá es más importante para la tranquilidad de las personas, la alimentación, que a su vez posibilita mantener una vida saludable y estar cerca de sus familias. De acuerdo con Roa Avedaño (2009), el sumak kawsay implica una estrecha relación con la tierra, con el cuidado y crianza de animales, con el trabajo, con la vida en comunidad, un mundo austero en equilibrio con la naturaleza y el mundo espiritual; considero que la gente de Ek Balam ejemplifica precisamente este tipo de lógica, ${ }^{22}$ donde el buen vivir, proviene del trabajo, de la capacidad de ser autosuficiente y consumir lo necesario; del vivir en paz, cerca de la familia y en relación respetuosa y agradecida con la naturaleza.

22 En su trabajo realizado entre mujeres tsotsiles de Zinacantán, María Eugenia Santana (2015), da cuenta de los valores asociados al buen vivir y que resultan similares a los destacados en Ek Balam. Tal es el caso de la relación entre el buen vivir con los espacios de vida y la cercanía con la familia, así como con las actividades del campo y la autonomía obtenida a través del trabajo de la tierra. 


\section{Ideas finales}

«Mirar» a Ek Balam y sus habitantes desde el desarrollo o el buen vivir ofrece panoramas completamente distintos. Por un lado, el desarrollo tiene que ver con vivir mejor, con alcanzar algo a futuro, con transformar; lo cual se puede hacer o hará a través del trabajo remunerado, es decir, con el turismo. Por otro lado, el «vivir bien» tiene que ver con el trabajo en la milpa, donde no se busca salir de la pobreza, ya que las personas no se consideran pobres, sino que se relaciona con tener lo necesario para vivir, con la alimentación, poseer salud, estar cerca de la familia y con la naturaleza. Así mismo, este trabajo tiene que ver con el conocimiento y los saberes obtenidos a través de las generaciones y no con un conocimiento externo.

Como señala María Larrea (2010), el desarrollo construye un «deber ser» que desvaloriza, invisibiliza los saberes, conocimientos y voces de los otros. Para el caso de Ek Balam, desde la visión del desarrollo, sus habitantes son representados como ignorantes, pobres, flojos y necesitados. Los agentes del desarrollo no prestan atención a sus experiencias, a su lógica de vida; son incapaces de mirar al otro y dialogar con él.

Las voces locales como las de Ek Balam ofrecen otras lógicas de vida desde las trincheras de la otredad, una otredad que históricamente ha sido objeto de intervención, de estudio, y que hasta el día de hoy sigue sometida a un proyecto civilizatorio occidental enarbolado por el desarrollo, en el cual, el otro es subalternizado (Handelsman 2011). El buen vivir representa una alternativa en tanto replantea las relaciones entre los seres humanos y la naturaleza, propone un nuevo horizonte de vida y una alternativa frente a la noción monocultural de la civilización occidental; nos permite reconocer los pensamientos no occidentales, como el pensamiento maya campesino que se expresa en las voces locales de Ek Balam. Como ya ha señalado Boaventura de Sousa (2010), es la hora de los y las invisibles, es momento de reconocer que los conocimientos y saberes de los indígenas, de los campesinos, son igual de valiosos que aquellos asumidos como verdaderos por el pensamiento occidental.

Es importante mencionar que el reconocimiento de los otros, implica la posibilidad del dialogo, aprender de y con ellos, romper con esa imagen del indio atrasado, flojo, ignorante y necesitado. Mientras el desarrollo avanza sin dialogo (Santana 2015), el buen vivir se encuentra directamente relacionado con una for- 
ma de diálogo intercultural alrededor de ciertos problemas fundamentales de la vida colectiva (Vanhulst 2015).

El tema a debatir es que la lógica del desarrollo, parece tener mucho mayor eco; es decir, parece abarcar cada día más a un mayor número de «adeptos», bajo distintas formas; mientras que la lógica del buen vivir parece ser algo que se va desvaneciendo y que no logra salir y enraizarse en otros sujetos aparte de aquellos que aún se sienten cercanos y a gusto con el tipo de vida que se encuentra contenida en esta lógica diferente a la del desarrollo.

La preocupación por la pérdida de este tipo de vida aparece claramente articulada al desapego que los jóvenes tienen con el trabajo campesino, el trabajo en la milpa; debido a que el mayor sustento de la lógica del buen vivir es el trabajo campesino, a través de éste se expresa una serie de creencias y prácticas que dan cuenta y contenido a la idea de una buena vida entre la gente «mayor» de Ek Balam, lo cual significa, tener milpa y de ahí obtener alimentos necesarios para comer; respetar la naturaleza, sus tiempos y a los «seres sobrenaturales»; la tranquilidad del pueblo y la cercanía con la familia, entre otras cosas.

\section{Fuentes de consulta}

Arce, Alberto, 2000, «Creating or regulating development: representing modernities through language and discourse», en Arce, Alberto y Normal Long (comps.), Anthropology, Development and Modernities. Exploring discourses, counter-tendencies and violence, Londres, Routledge, pp. 32- 51.

Comisión Nacional para el Desarrollo de los Pueblos Indígenas (CDI), 2012, «Programa Turismo Alternativo en Zonas Indígenas (PTAZI)», en <http://www.CDI.gob.mx/focalizada/ptazi/index.php> [consulta: 18/01/2012].

Dijk, Teun A. van, 2005, «Ideología y análisis del discurso», Utopía y Praxis Latinoamericana, 10(29), pp. 9-36.

Escobar, Arturo, 1995, Encountering development. The making and unmaking of the third world, New Jersey, Princeton University Press.

— 2000, «El lugar de la naturaleza y la naturaleza del lugar: ¿globalización o postdesarrollo», en Edgardo Lander (ed.), La colonialidad del saber: eurocentrismo y ciencias sociales. Perspectivas latinoamericanas, Buenos Aires, Clacso/Unesco, pp. 113-143.

_ - 2005, «El "postdesarrollo" como concepto y práctica social» en Daniel Mato (coord.), Políticas de economía, ambiente y sociedad en tiempos de globalización, Caracas, Facultad de Ciencias Económicas y Sociales, Universidad Central de Venezuela, pp. $17-31$.

_ 2008, Territories of Difference. Place, movements, life, redes, Londres, Duke University Press. 
Farah H., Ivonne y Luciano Vasapollo, 2011, «Introducción» en Ivonne Farah H. y Luciano Vasapollo (coords.), Vivir bien: ¿paradigma no capitalista?, La Paz, CIDES-UMSA, Sapienza y OXFAM, pp. 11-35.

Giovannini, Michela, 2014, «Indigenous community enterprises in Chiapas: a vehicle for buen vivir?» Community Development Journal, 50, pp. 71-87.

Gudynas, Eduardo, 2011, «buen vivir: Germinando alternativas al desarrollo», América Latina en Movimiento, 2(462), pp. 1-20.

Handelsman, Michael, 2011, «De la dominación al buen vivir: América Latina como proyecto civilizatorio "otro"», Guaraguao, 15(38), pp. 182-209.

Hobart, Mark, 1993, An Anthropological Critique of Development. The Growth of Ignorance, Nueva York, Routledge.

Huanacuni Mamani, Fernando, 2010, Buen Vivir/Vivir Bien. Filosofía, políticas, estrategias y experiencias regionales andinas, Lima, Coordinadora Andina de Organizaciones Indígenas (CAOI).

Instituto Nacional de Estadística y Geografía (INEGI), 2010, XII Censo de Población y Vivienda 2010, México, INEGI.

Larrea, Ana María, 2010, "La disputa de sentidos por el Buen Vivir como proceso contrahegemónico» Los Nuevos Retos de América Latina: socialismo y sumak kawsay, Quito, SENPLADES, pp.15-28.

León T., Magdalena, 2010, «El 'buen vivir: objetivo y camino para otro modelo», en Irene León (coord.), Sumak Kawsay/Buen Vivir y cambios civilizatorios, Quito, FEDAEPS, pp. 105-123.

Lizama Quijano, Jesús, 2007, Estar en el mundo. Procesos culturales, estrategias económicas y dinámicas identitarias entre los mayas yucatecos, Mérida, CIESAS.

Martínez Novo, Carmen, 1999, "Empresas mixtecas: "desarrollo" y poder en una cooperativa indígena en la frontera México-Estados Unidos» en Juan Carlos Gimeno y Pilar Monreal (eds.), La controversia del desarrollo. Críticas desde la antropología, Madrid, Instituto Universitario de Desarrollo y Cooperación, pp. 131-180.

Preston, P. W., 1999, Una introducción a la Teoría del Desarrollo, México, Siglo Veintiuno.

Rahnema, Majid y Victoria Bawtree, 1997, The Post-Development Reader, London, Zed Books.

Rist, Gilbert, 2002, El desarrollo: historia de una creencia occidental, Madrid, Catarata.

Roa Avendaño, Tatiana, 2009, «El sumak kawsay en Ecuador y Bolivia. Vivir bien, identidad, alternativa», Ecología política, 37, Barcelona, Icaria Editorial, pp. 15-19.

Santana E., María Eugenia, 2015, «El buen vivir, miradas desde dentro», Revista pueblos y fronteras digital, 10(19), pp. 171-198.

Santos, Boaventura de Sousa, 2010, «La hora de |@s invisibles» en Irene León (coord.), Sumak Kawsay/Buen Vivir y cambios civilizatorios, Quito, FEDAEPS, pp. 13-25.

Terán, Silvia y Christian Rasmussen, 2009, La milpa de los mayas, Mérida, Universidad de Oriente.

Tortosa, José María, 2011, «Sumak kawsay, suma qamaña, buen vivir», Aportes Andinos, 28, pp. 1-3. 
Truman, Harry, 1949, "Truman's Inaugural Addres», The Harry S. Truman Library and Museum, Presidential Libraries, National Archives and Records Administration, en <http://www.trumanlibrary.org/whistlestop/50yr_archiveinaugural20jan1949.htm> [consulta: 29/02/2012].

Tuz Chi, Lázaro Hilario, 2013, Aj Balam Yúumtsilo'ob: Cosmovisión e identidad en los rituales agrícolas de los mayas peninsulares, Mérida, SEGEY/Casa de la Historia de la Educación de Yucatán.

Vanhulst, Julien, 2015, «El laberinto de los discursos del Buen Vivir: entre sumak kawsay y socialismo del siglo XXI», Polis, 14(40), pp. 233-261.

Yapa, Lakshman, 1996, "What Causes Poverty?: A Postmodern View», Annals of the Association of American Geographers, 86(4), pp. 707-728. 